\title{
FUSION OF PRODUCT AND AUTOMATED-REPLICATIVE PRODUCTION IN CONSTRUCTION
}

\author{
Thomas Bock \\ Technische Universität München, Munich \\ thomas.bock@bri.ar.tum.de \\ Thomas Linner, Nora Eibisch, Willi Viktor Lauer \\ Technische Universität München, Munich \\ Thomas.linner@bri.ar.tum.de, nora.eibisch@bri.ar.tum.de, willi.lauer@,bri.ar.tum.de
}

\begin{abstract}
Traditionally we design, engineer and manage the product and production in construction separately. In biology or natural systems both are combined. The following paper will give an introduction to the notion of fusion of the construction as process and building as product phase. Advanced manufacturing concepts such as Konrad Zuse's "Self-Replicating Systems", had been partially implemented in Japans "Ghost Factories" and Taichi Ohno's Toyota Production Systems (TPS), all being predecessors of today's upcoming cognitive and responsive automated manufacturing systems. Further, the application of these systems in industrialized building and construction industry will be examined as the shift towards industrialized fabrication of more and more complex, customized and even user co-created unique products is of particular relevance for building industry demanding by its' nature for individual and unique outcomes. Recent concepts of Japanese building manufacturers even aim at making production not only responsive but also closed-loop through remanufacturing, recycling and re-customization of building modules. This again leads to the idea of "SelfReplicating Systems", envisioned by K. Zuse already in 1957.
\end{abstract}

\section{KEYWORDS: self reproduction, technology fusion, ghost factory, automated} replication

\section{INTRODUCTION}

Cybernetics and its approaches to handle complexity in various fields of applications as management, organization, engineering and biology, since the 1940's, can be identified as a basis for a new paradigm of interdisciplinarity between science and industries (Steinbruch, 1962). The renunciation of principles of mass production for the benefit of industrialized fabrication of more and more complex, customized and even user co-created unique products is an emerging paradigm (Kasanoff, 2009) which is of particular importance for building industry demanding by its' nature for strongly individual and unique outcomes (Linner, 2009). Moreover, demand oriented fabrication is likely to have a tremendous and lowering impact on resource and energy consumption and thus on long-term sustainability, both of which are problematic especially in construction industry (Bock et al., 2009). Today industrial production of individual products, which is also referred to as "Mass Customization" (Piller, 2006) is increasingly enabled in a multitude of industries through new production technologies, self-organizing production processes and material flows able to cope with dynamically changing economic environments: just-in-time, just-in-sequence, and 
just-on-demand. Accordingly, industry structures are developing from segmented factories, and hierarchical organization to non-hierarchical, flexible and decentralized production networks (EIMaraghy et al., 2008). Enablers for this shift are changeable and reconfigurable production systems (Wiendahl, 2008) and hyper-flexible modular production cells (ERTP, 2008) together with a high degree of permeation of information technology (Piller, 2006). In a next step industry and research facilities are aiming at so called "Cognitive Factories": highly flexible, self-organizing factories continuously adapting to changing economic surrounding and individual need (Zaeh et al., 2008). Cognition, autonomy and selforganization of increasingly complex production systems/organizations are a technological challenge, yet, they are a prerequisite for reducing the complexity of human intervention and thus reducing the cost of the customized product (Lindemann et al., 2006) to the cost level of a mass produced product.

The following paper will give an introduction to advanced manufacturing systems through examples given by Konrad Zuse's "Self-Replicating Systems", Japans "Ghost Factories" and Taichi Ohno's Toyota Production Systems (TPS), all being predecessors of today's and tomorrow's manufacturing methods. Further the application of these systems in industrialized building and construction industry will be examined. Konrad Zuse envisioned and recommended the introduction of highly customized production in building industry and Taichi Ohno's TPS has actually been transferred to industrialized just-in-time just-insequence production of individual houses through Toyota's Housing section. The modularization of building systems for industrialized production was done through Sekisui Heim's M1 concept following the paradigm of making production highly automated and autonomous. Later with the introduction of Information Technology for controlling complex production processes for individual buildings, another step towards autonomous and efficient mass customization was taken. Moreover, Sekisui Heim, today, with offering continuous rearrangement services and industrialized deconstruction and re-manufacturing/recustomization crosses the borderline towards real world closed-loop resource circulation, potential self-replication, and self-evolving production systems. Both Zuse and Ohno compared the essence of advanced, highly flexible and re-configurable next-generation manufacturing organization to fundamental principles that can be found in biological systems and biological evolution.

\section{KONRAD ZUSE: EXPERIMENTAL PROTOTYPE OF SELF REPLICATING SYSTEMS}

In biology the self-replicating systems are defined by the concept of autopoiesis since 1972 . In 1985 this concept has been adapted to describe social relationships. Self-replicating automata were first investigated by the mathematician and theoretical computer science pioneer John von Neumann. He proved that it is possible to build a Turing machine, programmed with the instruction to reproduce itself in its structure, and also to transmit its own program to its reproduction. Thus, it would be a self-replicating machine (Burks, 1970). In an article in the journal Nature 435/2006 structures of cellular automata are described, whose structures (n cubes) are composed of basic elements (cubes). The structure can replicate itself, if the base element (cube) is supplied from outside. The result is an exact reproduction of the original structure (Zykov et al., 2005). This experiment is a practical realization of the findings by John von Neumann. Already in the postwar-years Konrad Zuse developed his own concept of self-replicating systems. His thoughts were ahead of his time. 

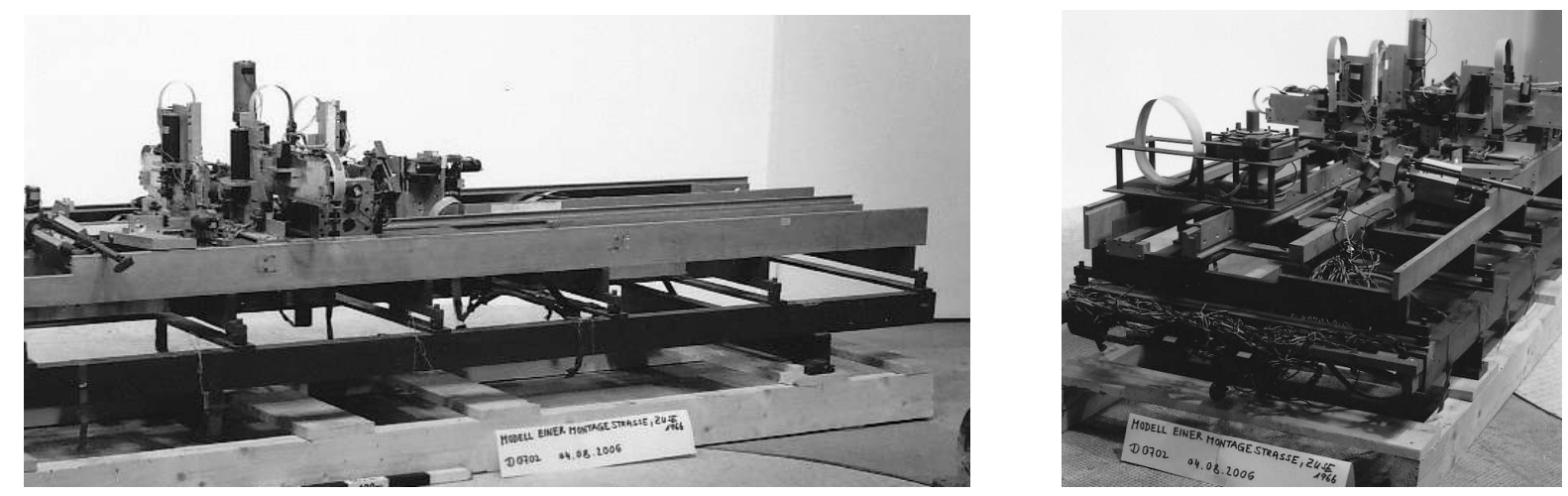

Figure 1, 2: Original Photos Prototype Self-Replicating Production System 1966 (copyright Deutsches Museum)
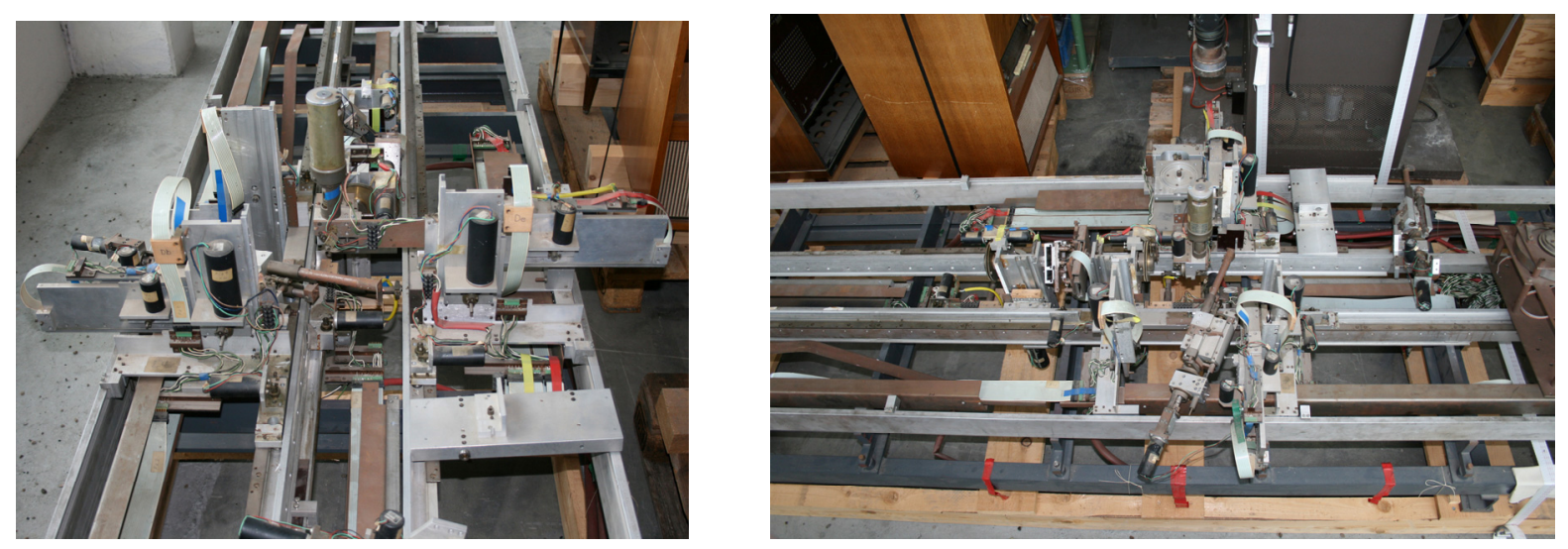

Figure 3, 4: Zuse' s Laboratory: Photos Prototype Self-Replication Production System, 2009

In 1957 Zuse publicaly stated his thoughts for the first time at the awarding of the Dr. Ing E. $\mathrm{h}$. of the TU Berlin. Zuse mentioned a "Technical Germ Cell" as a self-reconstructing machine or workshop. Out of this cell a complete industrial plant could emerge: In his speech Zuse recommends to not only focus on the production of mass-produced goods but rather also on customized goods. As a consequence new manufacturing processes would emerge and ultimately create entirely new social structures. As an example he mentions the building industry. He demands the automation of manufacturing processes to realize customized building projects. The fabrication parts could be self-produced in an automated manufacturing process. Such a process would have to both self-produce the respective parts as well as conduct their assembly in a closed unit. Such a manufacturing system could be a self-reconstructing machine. This machine could always reproduce its own structure. Zuse further mentions by reaching this level of technology the manufacturing processes could be influenced in such a way, that increasingly complex manufacturing facilities would arise. Thus we approach the Technical Germ Cell. The size of its components does not have to be fully defined from the beginning of such a process; the production is variable in scale. Zuse went so far as to formulate the idea of a production facility, which would be visible only under the microscope, and which could grow bigger through self-regulation. His conception of the self-replicating systems Konrad Zuse describes in more detail in an article published in the journal Elektronische Rechenanlagen, issue 9/1967. He describes the automatic reconstruction of production facilities as self-reproducing. He presents the idea of a universal factory, which gets raw materials and energy as input and has various products as output. A universal factory could be capable to produce its own means of production by itself and 
reproduce itself. If such a factory is provided by energy from its own power plants, this Technical Germ Cell can be compared with nature, especially with the organization of a cell, whose progeny entirely depends on delivery of raw material. In his article Zuse expresses futuristic ideas that are closer to the limits of feasibility today. The methodology of organizing production as described by Zuse is still novel at present. Henry Ford as an automobile manufacturer and a pioneer of automated manufacturing processes had already tried to implement the idea of an autarkic factory. This way he planned to reach independence from market prices and market developments. As Zuse 1967 schematically describes in his article current mass production of customized goods is only possible via national and international networking, improved information flow and advanced logistics. Today the automotive industry goes farther away from Ford's idea of the autarkic factory. The manufacturers, e.g. Smart, order completely assembled car-components like the chassis from their suppliers. Zuse's ideas as described in his article still have not been realized today. A diagram shows a mechanical system in which the manufacturing process initially consists only of assembly. This schema describes the "assembly line" that was constructed by Zuse in the 1970s (Figures 1-4). The "assembly line" is located in the collection of the Deutsche Museum in Munich together with the estate of the inventor. Zuse was aware of the works by the mathematician John von Neumann. According to Zuse the theoretical ansatz to the Technical Germ Cell by von Neumann was only of limited use in practice. The computer pioneer tried to put the idea into practice by construction of the "assembly line". The "assembly line" has 26 degrees of freedom. In 1974 Zuse renamed the research project "assembly line SRS72" in "industrial handling". Whether he accepted an offer to work on the project "Industrial Robots", in which companies like Pfaff, Daimler-Benz and M.A.N. were involved, is not known yet. In 1971 Zuse articulated the importance of the research project "assembly line SRS72" as follows: About a billion years ago, nature developed biological systems in the form of cells that are capable to reproduce themselves. This event was one of the most important in the evolution of life as it constituted the precondition for the further development of complete organisms. Development and construction of self-reproducing systems have the goal to transfer this phase of biological evolution to technology. (DMA, NL 220, vorl. Nr. 379/88: Konrad Zuse in a letter dated 19.12.1971).

\section{GHOST FACTORIES AND THE AUTOMATION OF MANUFACTURING}

The fully automated production today is an important foundation of innovation for industry. For the first time the technological frontier to fully automated production had been reached at the beginning of the 80s in Japan. What Konrad Zuse envisioned about 20 years before as self-reproducing systems has now been put into reality with factories in which 2 of 3 production phases were completely and autonomously controlled by machines and robots. In the Minokamo factory of the Yamazaki Corporation and Yamanashikomura factory of the Fanuc Corporation all work tasks were done by robots and autonomous self-guided vehicles that commissioned flexible manufacturing centres. This so called "Ghost Factory" produced (compared to the later described complex prefabricated buildings) relatively simple servo motors and other manufactured parts for machine tools, CNC machines used in flexible manufacturing centres similar to the "Ghost Factory" itself. So the factory potentially would have been able to re-produce itself to high degree autonomously. The Ghost Factories in Japan the 80's therefore can be classified as fundamental prototypes in the development to more and more complex and autonomously self-organizing production systems. 


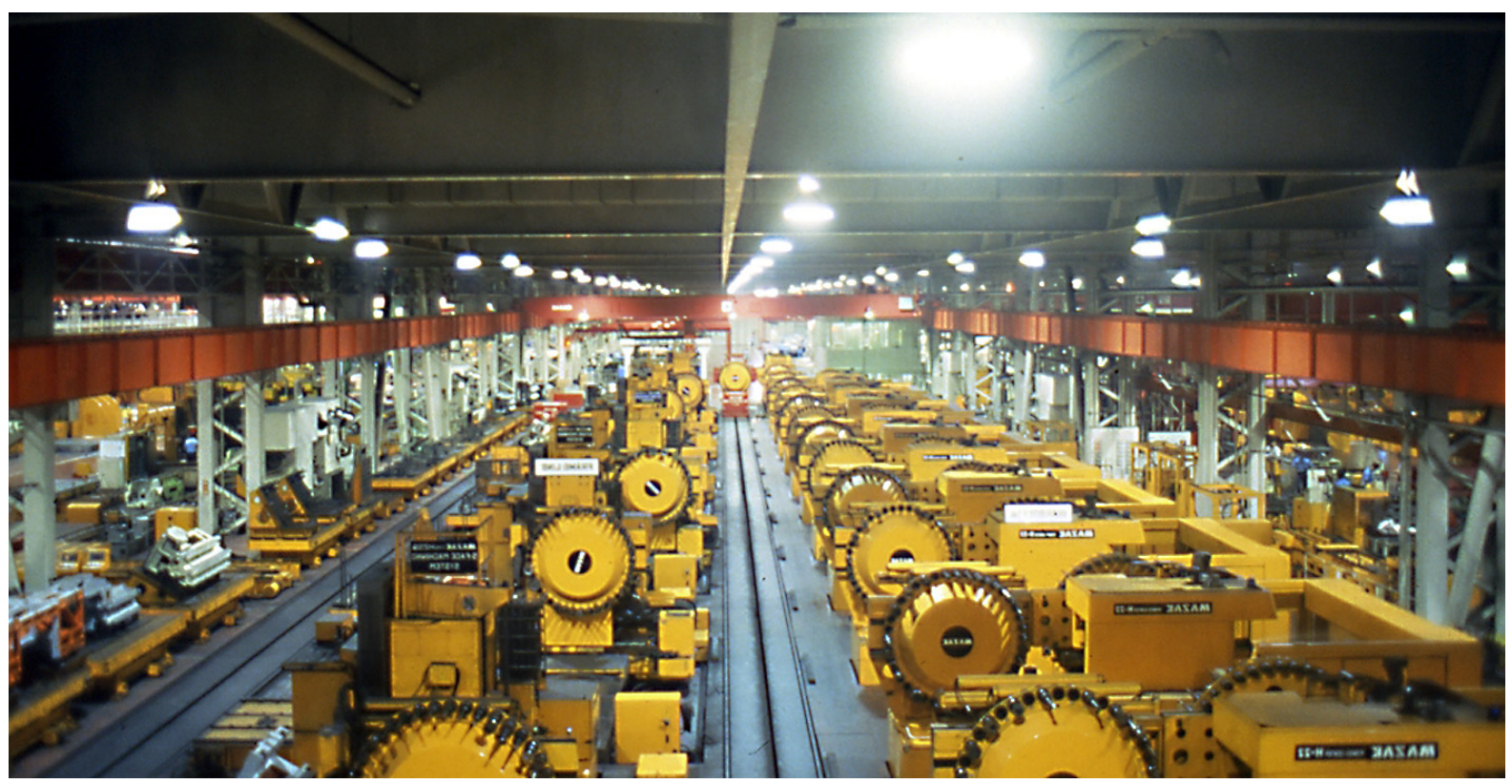

Figure 5: Fully automated Minokamo „Ghost Factory“, Yamazaki Corporation, Japan

\section{AUTOMATED BUIDLING PRODUCTION}

More advanced than the relatively simple linear manufacturing of machine parts/tools is the continuous production of houses from individual and prefabricated cells offering new possibilities to shift construction towards continuously industrialized and controlled factory production. Japanese manufacturers as Sekisui Heim, Toyota and Misawa Home break down a unique family house into 10-15 units each being individual and finish them in the factory up to a degree of $85 \%$. Into those units a multitude of other three-dimensional subsystems from various suppliers (e.g. bath/kitchen modules) are integrated in production line based factories. This production method has now been used and developed further in Japan since almost half a century and it shows many analogies to automotive production. It shows that a continuous production line processing becomes possible through the introduction of a three-dimensional steel frame being used as "chassis". This "chassis" support structure is processed with a speed $1.4 \mathrm{~m}$ per minute over 45 workstations on a conveyor belt which is about $400 \mathrm{~m}$ long. In this process it is partly automatically equipped and finished sequentially from all sides with components that are either supplied just-in-time or that have been produced in parallelized processes on different floors (e.g. wall panels). One of the main reasons of Sekisui, Misawa Toyota for applying this production method instead of conventional construction is to shift the complexity of the creation process as much as possible to the controlled factory environment. There it is possible to finish the product to a high extent minimizing the processes which cannot be controlled. The unit cells are finished in one of the factories which are set up throughout Japan and then shipped to the site where they are assembled to a basically weatherproof construction within nine hours. Minor finishing works are performed within the following 4 weeks. All required joints and jointing compounds are pre-sorted and structurally arranged so that at the site itself not more than 4 trained workers are required. The productivity of this production method is so high that annually, depending on the capacity utilization, per employee 3 to 4 buildings can be realized. Further, analysis shows that prefabricated houses are in particular favoured among better-off social classes as they are 
of high-quality and reliability. An important role for the positive image of prefabrication in Japan plays the general fascination for technology as well as proven earth quake resistance and well known rigid quality checks done throughout the whole production process.

\section{Sekisui Heim M1 - Design for Production}

Kazuhiko Ohno developed in 1968 as part of his thesis at the Tokyo University the legendary M1 system adopted and brought into large-scale production by Sekisui Heim. This threedimensional building component system was marked in particular by its simplicity and genius. It has been able reduce the complexity to such an extent that an industrial assembly line production became possible. The M1 united qualities that up to this point had not yet been brought together. Initially, this was the first time that a unit and steel based system perfectly suited for the sub sequential industrialized production. Additionally, through distinct modular and hierarchical differentiation of components, it was possible to fabricate an initially small number of building variants with high efficiency out of an even smaller number of components making the system highly efficient. Finally the architectural expression, which took advantage of the modular structure as a design element, was characterizing the M1. This feature tended to get lost in later Sekisui models based on customer's requirement and market constraints. In the 70s, the M1 reached a sensational annual production of over 3000 buildings/year over a long period of time. This high annual production allowed the investment in expensive manufacturing systems (e.g. automation, robotics, logistic systems) which today make up the uniqueness of the Japanese prefabrication industry. With combining standard room modules and layouts, the choice and the integration of customers in the creation process of an M1 was still comparatively low, which, in the following, however, should change rapidly.

\section{TPS: Self alignment of a production system to changing demand}

An important development to large-scale industrialized and customized manufacturing of buildings has been done by Toyota through the transfer of the legendary Toyota Production System into the production of buildings completed by the mentioned cell/unit prefabrication method. The Toyota Production System was invented after the Second World War, when the Toyota Motor Corporation was looking initially for a way to increase productivity in order to compete with the American icons of mass production. A visit to Ford and General Motors brought for Toyota management the insight that a manufacturing strategy based on mass or variant production and "economies of scale", never would work successfully in Japan's fast and continuously changing social and economic system. Already at that time Japan had quite sophisticated and rapidly changing markets, requiring a production of small series down to a production batch of one individual product. Additionally, Toyota feared the impact of a global recession and suspected that industrial enterprises aiming at producing large quantities of a standardized product (= Mass Production), could survive an economic crisis only with huge losses (Taichi Ohno). How much foresight Toyota had with introducing the TPS strategy aiming at sustainability and conservation of resources, can be seen today: The crisis feared actually occurred, and it requires exactly the tribute, which Toyota was not willing to pay; especially mass producers are hit by the crises. Out of these backgrounds, the Toyota Production System (TPS) had been developed. The basic idea of TPS was to reverse the straightforward material and information flows of mass production ("Pushing Production") and thus come to an individualized production, which consistently makes the necessity of an individual customer to the starting point of any production ("Pulling Production"). With a 
production and management system that is uncompromisingly imbued with information technology, Toyota has built an infrastructure that can align dynamically to the individual wishes of many individual customers. Having reached this stage of development in production technology, the introduction of industrial processes in the Japanese construction industry was a relatively easy step to be taken: In Japan as well as in Europe building are strong links with the idea of individuality, but especially in Japan the gap between the continuous rationalization of processes and simultaneous and continuous individualization of the final products has already been overcome. The transfer of this system in the mid-70s in to the ambitious Prefab industry was an important step in the further evolution of automated and customized prefabrication in the building industry. Today in the factories of Toyota and Sekisui Heim units/cells are moved on a conveyor belt through the factory where they are customized just-in-time just-in-sequence to the required configurations. Yet, the ideas of T. Ohno went far beyond Kanaban and the transfer of his system into housing industry. In his 1988 book "Beyond Large Scale Production" - the first publication about the TPS system - T. Ohno already envisioned the rising complexity through individualized production and suggested what today is referred to as "Cognitive Factory". Accordingly to Ohno, organization's and production entities' alignment to changing surroundings, dynamical markets and individual products should be performed through a high degree of selforganization similar to that of the human body: The organization of a company is supposed to look like that of the human body. The human body has autonomic nerves (autonomic nervous system) and motor nerves, which he can control for movements voluntarily (peripheries nervous system). The human body thus has a surprisingly elaborate structure and function ... At Toyota, we began to think about how we could build an autonomic nervous system in our increasingly complex corporate structure (Ohno, 1988).

\section{Sekisui Heim - expert systems and continuous information flows}

After the introduction of TPS and demand as well as customer-oriented manufacturing into the industrial production of buildings by Toyota, this system was soon adopted and developed further by Sekisui Heim, the inventor of the unit and production line method in building industry. In the 80s it was now Sekisui Heim which brought forward industrialized and individualized building production through the utilization of complex expert systems. This state's another crucial invention in the evolution of customized industrialization as information technology turns out to be a key technology for effectively linking customers to products and production systems. Sekisui Chemical, a tall, broad-based group with diverse business areas (plastics, infrastructure, housing, environmental and energy technologies), one of which Sekisui Heim was, commissioned the development a computerized expert system that should support the control and efficient management of input resources, production processes and just-in-time just-in-sequence demand oriented logistics. The system was finally introduced to Sekisui Chemical's house section Sekisui Heim. Since then it had been developed further in many generations and is now known as HAPPS (Heim Automated Parts Pickup System). HAPPS was one of the first parameter-based systems that allowed translating architects' and/or customers' desired floor plans directly into production sequences and logistics and work tasks. Further HAPPS also allows for managing and dynamically aligning the building component system. It can also be used to develop new product platforms and variants out of existing components with a high degree of automation. With the help of HAPPS are now produced annually about 13,000 homes. This means that a large factory per day produces about 135 completed and industrially customized unit modules (= a "unit", every 3 minutes). Customized production demands that out of a continuously 
changing solution space of more than 300.00 listed parts, about 30.000 parts building up an average sized house have to be chosen correctly and have to be synchronized just-in-time just-in-sequence with the $400 \mathrm{~m}$ long assembly line in an optimized way meanwhile a multitude of parallel working processes has to be controlled. HAPPS links the information about customers and individual demands to the process of economic transformation of input resources into output products with a high degree of immediacy and automation.

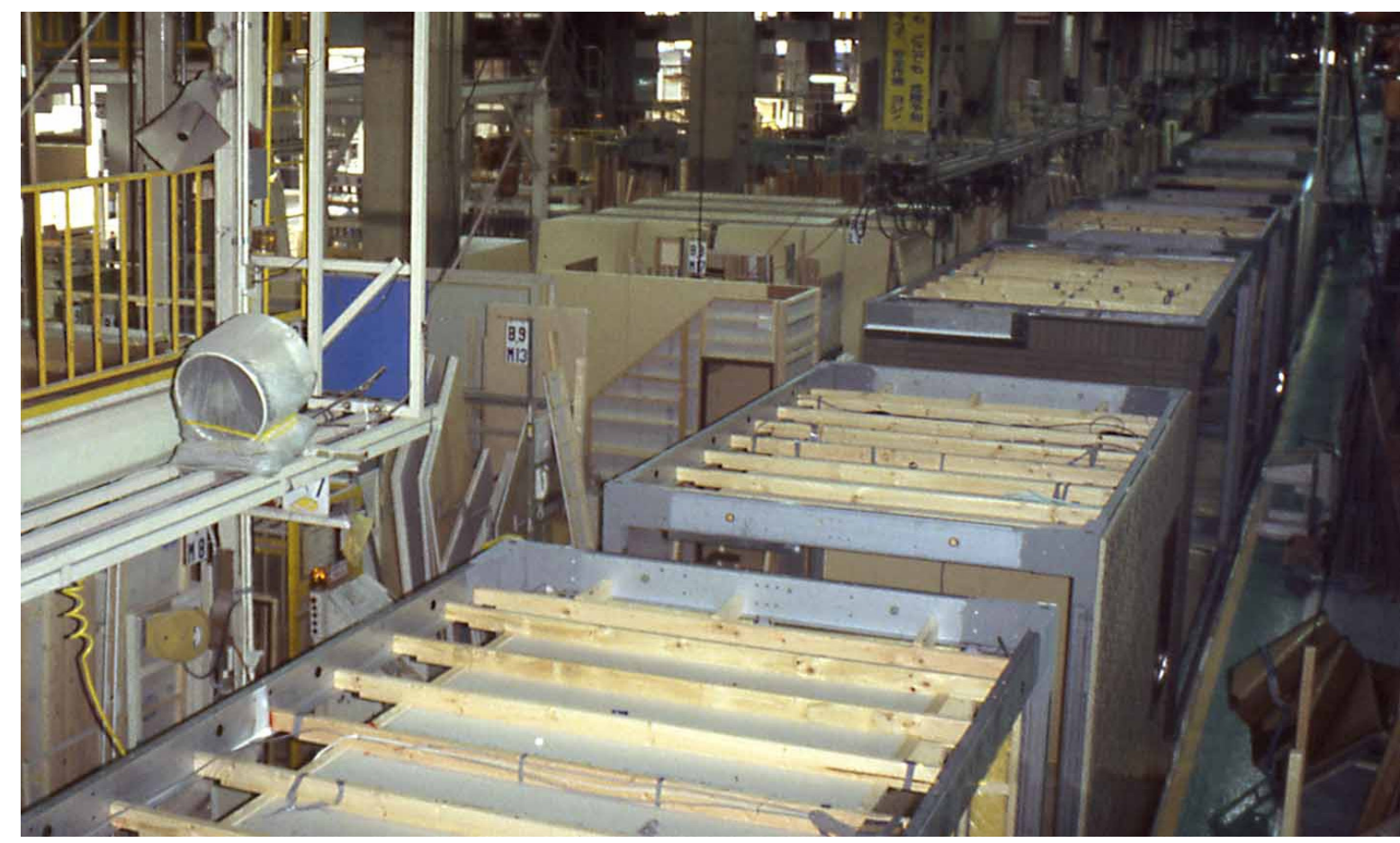

Figure 6: Automated and Continuous Prefabrication of buildings on the production line

\section{CLOSED-LOOP RESOURCE CIRCULATION}

The production processes of both Sekisui Heim and Toyota Home are characterized by a high percentage of automated, self-adjusting and robot supported processes meanwhile the production outcomes become more and more customized. Through continuous improvements customers are gradually deeper integrated into the production process without thereby creating additional costs. Further Japanese companies try to extend their business from pure on-point customization to a type of customization which can adapt houses continuously and dynamically over time. This is achieved through two types of ongoing and industrialized customization. Firstly, companies try to exploit the value of their modular designs to a higher extent by offering systemic "upgrade packages". This means that distinct modules, components or subsystems can be exchanged by new industrially prefabricated ones to adjust the house to changed circumstances, needs or tastes. Secondly, Sekisui Heim with its "System Reuse House" offers the possibility that the modular units once fabricated in the factory are disassembled from their location and brought back to the factory. In the factory sub-systems and sub-components are disassembled from the bearing "chassis" support structure which is then subsequently equipped with new ones. This transformation process allows that a house is re-customized and even re-located at another place suiting the individual customer. The disassembled components can additionally be reused or recycled 
with high efficiency through the dismantling process taking place in a controlled factory environment feeding them again into new industrial transformation circles. The idea of a similar system Konrad Zuse pursued in the early 1990s with the invention of the HelixTower. The Helix-Tower is a continuously extendable and retractable mast. The mast is a tube, built through single uniform shell segments. In the planned implementation of his project Zuse saw a symbol of the principle of his self reproducing systems (Alex, 1997).

\section{CONCLUSION}

To be able to perform „on-point” or „over-time“ customization, the setup of the enterprise and its transformation and/or production system has to be able to adjust continuously over time to new circumstances. Thereby its sub-entities have to organize themselves to a high degree autonomously in order to reduce the complexity of human intervention and thus to reduce the cost of the customized product/house to the cost level of a mass produced product/house. If a production transformation system cannot perform this complexity and cost reduction through a high level of autonomous information and resource processing and automated self-organizing sub-processes it will not survive against mass production. To be able to meet these requirements, an industrial transformation system has to be similar to a biological organism or ecosystem which continuously transforms/optimizes itself over time and adjusts to new circumstances. With Sekisui Heims' system of remanufacturing and recycling the production and resource cycle is closed-loop, units will be withdrawn and exchanged against newly customized ones continuously, production facilities adapt and reconfigure to new circumstances over time. Taken one step further this indeed leads to the idea of self-reproducing systems as envisioned by K. Zuse. If the system for example is set equal not only to a single company but to a whole industry, town or nation such industrialized and closed loop-production cycles adapting semi- or fully autonomously to shifting needs or demands, it have tremendous impact on economy, society and ecology. Those systems would then be able to continuously produce anything from simple goods to complex buildings personalized to our demand - yet with just the input needed, eliminating any waste and minimizing environmental impact. My space generatig machine is nothing else than a vague vision, to send devices into the environment, which first produce materials out of synthesized organics by the use of nuclear, or solar power, and to manufacture elements out of these, which produce spatial structures by stringing together these elements. Afterwards these structures will be dissoluted by the same process, as there should be no waste in the environment. (Wachsmann, 1989) Visions of continuously transforming and adjusting sustainable environments or cities as proposed by Japanese Metabolists (Lin, 2010), European Archigram Group (Cook, 1999) and Habraken's/Kendall's Open Building Approach (Habraken, 2000; Kendall, 2000) could together with the mentioned selfreplicating, semi-autonomous and cognitive production systems build the backbone of future sustainable cities. Today such type of factory in a broader sense is still hard to handle as not yet mechanisms for autonomous self-organization of multiple and complex entities have been developed. Further research will examine more detailed the applicability of fundamental principles of biological systems (T. Ohno) and biological evolution (K. Zuse) for the development of future responsive productions systems. 


\section{REFERENCES}

1. Alex, J. (1997) Wege und Irrwege des Konrad Zuse, In: Spektrum der Wissenschaft 1/1997 pp. 78-90

2. Bock, T., Linner, T., Lee, S.Y. (2009) Integrated Industrialization Approach for lean On-/Off-site Building Production and Continuous Resource Circulation. Proceedings of $7^{\text {th }}$ Global Conference on Sustainable Manufacturing

3. Burks, A. (1970) Essays on Cellular Automata, Illinois

4. Cook, P. (1999) Archigram. NewYork: Princeton Architectural Press

5. EIMaraghy, H., Wiendahl, H. (2008) Changeability - an Introduction. In: Changeable and Reconfigurable Manufacturing Systems. Berlin: Springer. pp. 03-23

6. ERTP (2008) European Robotics Technology Platform. www.robotics-plattform.eu

7. Furuse, J., Katano, M. (2006) Structuring of Sekisui Heim automated parts pickup system (HAPPS) to process individual floor plans. Japan: ISARC 2006 International Symposium on Automation and Robotics in Construction

8. Habraken, N.J. (2000) The Structure of the Ordinary - Form and Control in the Built Environment. The MIT Press

9. Kasanoff, B. (2009) The Personal Economy. Keynote, MCPC2009 Conference on Mass Customization, Personalization and Co-creation, Helsinki, Okt. $2009-$ www.nowpossible.com: How to create markets for one person

10. Kendall, S., Teicher, J. (2000) Residential Open Buidling. International Council for Building Research Studies, CIB

11. Lin, Z. (2010) Kenzo Tange and the Metabolist Movement: Urban Utopias of Modern Japan. Routledge

12. Lindemann, U. Reichwald, R., Piller, F.T. (2006) Individualized Product. Berlin: Springer

13. Linner, T., Bock, T. (2009) Smart Customization in Architecture: towards intelligent buildings. Proceedings World Conference on Mass Customization, Personalization and Co-Creation (MCPC), Helsinki

14. Ohno, T. (1988) Toyota Production System - beyond large scale production, Massachusets: Productivity Press

15. Piller, F.T. (2006) Mass Customization. Wiesbaden: Deutscher Universitätsverlag

16. Sekisui Heim (2010) Japan, System Reuse House, available at: www.sekisuichemical.com/about/division/housing/reuse.html

17. Steinbuch, K., Frank, H., Kretz, H., Meves, H., Küpfmüller, K., Keidel, W.D., Schwartzkopff, J., Feldtkeller, R., Wenzel, F. (1962) Kybernetik - Brücke zwischen den Wissenschaften. Umschau Verlag, Frankfurt am Main

18. Wachsmann, K. in Otto Maier, Die Räumliche Syntax, 1989, pp.186

19. Wiendahl, H. (2008) Adaptive Production Planning and Control - Elements and Enablers of Changeability. In: Changeable and Reconfigurable Manufacturing Systems. Berlin: Springer. pp. 197-211

20. Zäh, M.F., Beetz, M., Shea, K., Reinhardt, G. (2008) The Cognitive Factory. In: Changeable and Reconfigurable Manufacturing Systems. Berlin: Springer. pp. 355-369

21. Zuse, K. (1967) Über sich selbst reproduzierende Systeme. In: Elektronische Rechenanlagen 9/1967

22. Zykov, V., Mytilinaios, E., Bryant, A., Lipson, H. (2005) Self-reproducing machines, Nature Vol. 435, pp. 163-164. 